\title{
Solitary Bone and Extramedullary Plasmacytoma
}

\author{
Galina Salogub, Ekaterina Lokhmatova and Sergey Sozin \\ Saint Petersburg State Medical University n. a. I.P.Pavlov \\ Russian Federation
}

\section{Introduction}

Plasmacytomas are clonal proliferations of plasma cells that are cytologically and immunophenotypically identical to those of plasma cell myeloma, but manifest a localized osseous or extraosseous growth pattern (Jaffe et al., 2001).

Solitary plasmacytomas are tumors of plasma cell origin that constitute less than $10 \%$ of all plasma cell neoplasms (Osserman, 1959) with a slightly lower median age of approximately 63 years (Hernandez et al., 1995).

The World Health Organization classification recognizes solitary plasmacytoma of bone (solitary bone plasmacytoma, SBP) and extramedullary / extraosseous plasmacytoma (EMP) (Jaffe et al., 2001).

The International Myeloma Working Group (IMWG) recognizes solitary plasmacytoma of bone, extramedullary plasmacytoma and multiple solitary plasmacytomas (+/-recurrent) as distinct entities (The International Myeloma Working Group. Criteria for the classification of monoclonal gammopathies, multiple myeloma and related disorders: a report of the International Myeloma Working Group, 2003).

\section{Solitary bone plasmacytoma}

\subsection{Epidemiology and clinically-laboratory features}

Solitary bone plasmacytoma has a male:female ratio of 2:1, with a median age of 55 years and primarily affects the axial skeleton especially the vertebrae (Dimopoulos et al, 2000) (Table 1). Osseous lesions constitute approximately $70 \%$ of all plasmacytomas. They involve primarily marrow-containing bones, with a predilection for the vertebrae, femurs, and pelvis (Bolek et al., 1996).

Malignant bone tumours of the spine are extremely rare $(<0,05 \%$ of primary neoplasms). Solitary plasmacytoma is the commonest separate entity within this group, accounting for approximately 30\% of the total (McLain \& Weinstein, 1989). These tumours occur in the spine twice as often as other bony sites (Chang et al, 1994).

The most common presenting symptom is pain due to bone destruction, but patients with vertebral involvement may also have evidence of spinal cord or nerve root compression. 
A few patients with solitary bone plasmacytoma present with symptoms and signs of demyelinating polyneuropathy. In evaluating such patients, the syndrome of polyneuropathy, organomegaly, endocrinopathy, $M$ protein, and skin changes (POEMS) should be considered. Involvement of the base of the skull can present with cranial nerve palsies (Vaicys et al, 1999;Vijaya-Sekaran et al, 1999).

\begin{tabular}{|l|l|l|}
\hline & SBP & SEP \\
\hline Age (years), median & 55 & 55 \\
\hline M:F & $2: 1$ & $3: 1$ \\
\hline Predominant site & $\begin{array}{l}\text { Axial skeleton, } \\
\text { especially vertebrae }\end{array}$ & Head and neck \\
\hline$\%$ with M protein & 60 & $<25$ \\
\hline$\%$ developing MM & $>75$ & $<30$ \\
\hline$\%$ survival at 10 years & $40-50$ & 70 \\
\hline
\end{tabular}

Table 1. Clinical features of solitary bone plasmacytoma and extramedullary plasmacytoma (United Kingdom Myeloma Forum, Guidelines on the diagnosis and management of solitary plasmacytoma of bone and solitary extramedullary plasmacytoma, 2004).

The involvement of the nervous system is a common complication of plasma cell neoplasms. Cranial myelomas (osseous, such as skull bones) and intracranial myelomas (other than bones, ie, extramedullary, such as hypothalamus) can be broadly classified into three clinical groups (Moossy et al. 1967) as shown in Table 2.

\begin{tabular}{|l|l|l|l|}
\hline Group & Syndrome & Involvement & Clinical Picture \\
\hline I & cranial nerve palsies & base of the skull & $\begin{array}{l}\text { single or multiple } \\
\text { cranial nerve palsies }\end{array}$ \\
\hline II & intracranial tumor & $\begin{array}{l}\text { - cranial myeloma } \\
\text { extending } \\
\text { intracranially } \\
\text { - lesions that are } \\
\text { entirely intracranial }\end{array}$ & $\begin{array}{l}\text { similar to a primary } \\
\text { brain tumor }\end{array}$ \\
\hline III & intraorbital tumor & orbit & $\begin{array}{l}\text { orbital space- } \\
\text { occupying lesion }\end{array}$ \\
\hline
\end{tabular}

Table 2. Involvement of Nervous System in Plasma Cell Neoplasms

Plasmacytoma involvment of petrous bone causes dysphagia secondary to lateral medullary syndrome (it is one of the brainstem vascular syndromes that occur due to the occlusion of posterior inferior cerebellar artery or one vertebral artery, which may lead to dysphagia, vertigo, vomiting, ipsilateral paralysis of soft palate, ipsilateral Horner's syndrome, ipsilateral hypotonia and ataxia, and dissociated sensory loss) and results in paralysis of the 10th and 12th cranial nerves. The body of the sphenoid and the apex of the petrous bone are the most common sites of involvement. The tumors may be either small or discrete, or they may grow to large dimensions. These lesions have a greater tendency to expand locally rather than to disseminate, a property that may be controlled by specific cytokines (Mill et al., 1980). The bone is probably the site of origin; however, they may arise from mucosa contained within the sphenoid and petrous bones, since non-osseous myelomas are common. 
The cranial nerves can be affected either by local distortion or by direct destruction, such as that which occurs with invasion of the cavernous sinus or jugular foramen region. Other cause of the neuropathy with chronic and slowly progressive course may be an axonopathy with secondary demyelination. High titers of anti-MAG (myelin-associated glycoproteins) are seen in patients with neuropathy. Involvement of the 5th, 6th, and 8th cranial nerves is most common (Moossy et al., 1967).

An intracranial plasmacytoma is a rare form, which can involve the calvarium, dura or the cranial base. It could manifest with majority of neurological symptoms, such as headache, diplopia, gait disturbances, hypoesthesia and areflexia of extremities, personality disorder and many others. Intracranial plasmacytoma may be cause of acute or chronic intracerebral hemorrhage. (Goyal et al., 2006; Crowley et al., 2010)

Intraorbital localization of plasmacytoma may present with exophthalmos, increased tearing, blurred vision, also diplopia or unilateral loss of vision (Wachter et al.,2010; Brandon Hayes-Lattin et al., 2003).

\subsection{Diagnosis and investigation of SBP}

\subsubsection{Diagnostic criteria}

- $\quad$ single area of bone destruction due to clonal plasma cells;

- $\quad$ histologically normal marrow aspirate and trephine ( $<5 \%$ plasma cells);

- normal results on skeletal survey, including radiology of longbones;

- no anaemia, hypercalcaemia or renal impairment due to plasma cell dyscrasia;

- $\quad$ absent or low serum or urinary level of monoclonal immunoglobulin (level of $>20 \mathrm{~g} / 1$ suspicious of multiple myeloma);

- o additional lesions on magnetic resonance imaging (MRI) scan of the spine.

(United Kingdom Myeloma Forum. Guidelines on the diagnosis and management of solitary plasmacytoma of bone, extramedullary plasmacytoma and multiple solitary plasmacytomas: 2009 update).

\subsubsection{The recommended investigations}

- full blood count

- biochemical screen including electrolytes and corrected calcium

- $\quad$ serum immunoglobulin levels

- $\quad$ serum and urine protein electrophoresis and immunofixation

- $\quad$ serum free light chain assay

- full skeletal survey

- $\quad$ MRI of spine and pelvis (or skeletal survey by MR where this facility exists)

- bone marrow aspirate and trephine

- $\quad$ PET scanning may be useful in selected patients.

(United Kingdom Myeloma Forum. Guidelines on the diagnosis and management of solitary plasmacytoma of bone, extramedullary plasmacytoma and multiple solitary plasmacytomas: 2009 update). 


\subsubsection{Laboratory}

SBP should be diagnosed by tissue biopsy. Fine needle aspirate is inadequate. (United Kingdom Myeloma Forum. Guidelines on the diagnosis and management of solitary plasmacytoma of bone, extramedullary plasmacytoma and multiple solitary plasmacytomas: 2009 update).

Percutaneously guided biopsy of the spine is usually possible either by fluoroscopy or CT. All diagnoses should be made or reviewed by specialist haematopathologists in accordance with NICE guidelines for improving outcomes in haematological cancers (NHS NICE Improving outcomes in haematological cancers 2003. www.nice.org.uk).

When a bone tumor is encountered which is histopathologically diagnosed as 'small round cell tumor', the differential diagnosis includes Ewing sarcoma, osteosarcoma of small cell type, malignant lymphoma, plasmacytoma, metastatic small cell lung cancer and so on.

The bone marrow of patients with SPB should have no clonal plasma cells. But some patients may demonstrate up to 10 percent clonal plasma cells, and are considered as having both SPB and monoclonal gammopathy of undetermined significance (MGUS). These patients may have a higher risk of progression to symptomatic myeloma. If patients suspected to have SPB have 10 percent or more clonal plasma cells in the bone marrow, they should be considered to have Durie-Salmon stage I myeloma rather than SPB.

Immunophenotyping. Monoclonality and / or an aberrant plasma cell phenotype should be demonstrated with useful markers being CD19, CD56, CD27, CD117 and cyclin D1 (Rawstrom A.C, 2008).The immunophenotyping of bone marrow plasma cells in SBP has not been investigated so far and since a significant number of these patients progress to multiple myeloma. It is possible that the bone marrow of patients with SBP might contain neoplastic PC at the time of diagnosis, which may correlate with risk of progression to multiple myeloma. Maayke et al. demonstrated by flow cytometry, that aberrant phenotype plasma cells present at distant bone marrow sites in $67 \%$ of patients with solitary plasmacytoma of bone (Maayke et al., 2010). In the report of Bhaskar et al., plasma cells were easily identified based on dual expression of CD38 and CD138 in the bone marrow aspirates and varied from $0.17 \%$ to $1.05 \%$. The neoplastic as well as normal PC were seen in the bone marrow aspirates of all the cases at the time of diagnosis and ranged from $0.10 \%$ to $0.70 \%$ and $0.06 \%$ to $0.49 \%$ of all the bone marrow cells respectively (Bhaskar et al., 2009). The authors suggest, that aberrant immunophenotype rather than the light chain restriction pattern was useful in identification of low number of neoplastic plasma cells in the bone marrow as the $\kappa: \lambda$ ratio was normal in all the samples (range: $0.5 \%$ to $1.6 \%$ ). However, small number of cases studied and the relatively short duration of follow-up preclude a definitive opinion on value of these findings at this time. But given the ease of flow cytometric quantitative detection and enumeration of neoplastic PC in the bone marrow, additional studies for prognostic value determination are needed.

Cytogenic. Cytogenetic studies in SBP reveal loss in chromosome 13,1p, 14q, gain in 19p, 9q, 1q and IL-6 is considered as the principal growth factor in the pathogenesis (Christopher DM Fletcher. Diagnostic histopathology of tumors. Volume 2, 2nd edition. Churchill Livingstone). 
M-protein and serum free light chain assay. The presence of monoclonal protein (M protein) in the serum or urine has been noted in $24 \%-72 \%$ of patients in various series (Dimopoulos MA, 2000, 2002). In experience of M.D.Anderson Cancer Center (Weber D. 2005), among 63 consecutive previously untreated patients with SBP, $62 \%$ had a serum $M$ protein, $13 \%$ had only Bence Jones protein (BJP), and $25 \%$ had non-secretory disease. Paraprotein values were usually very low, with only 11 of 37 patients with a serum M protein $>1 \mathrm{~g} / \mathrm{dL}$ (high value $2.2 \mathrm{~g} / \mathrm{dL}$ ) and the highest urine BJP was $0.7 \mathrm{~g} /$ day.

Recently, free light chain assays have provided a measurable parameter to follow in approximately $65 \%$ of patients previously diagnosed with "nonsecretory" multiple myeloma by standard electrophoretic studies (Drayson MT, 2001). In report of Frassica et al. on 46 patients with SBP, 25 (54\%) had a detectable serum or urine M-protein, 4 patients had an M-protein in both serum and urine, while 1 patient had only Bence Jones proteinuria (Frassica et al., 1989). The M-protein may decrease with successful therapy of SBP, and it has been reported that complete disappearance of the M-protein 1 year after therapy is associated with prolonged disease stability (Liebross et al., 1998; Wilder et al., 2002).

Uses of the serum free light chain (SFLC) assay has the prognostic value in solitary plasmacytoma (Dispenzieri et al., 2008): an abnormal serum immunoglobulin free light chain (FLC) ratio at diagnosis may identify risk of progression to myeloma in patients with solitary bone plasmacytoma. The risk of progression at 5 years was $44 \%$ in patients with an abnormal serum FLC ratio at diagnosis compared with $26 \%$ in those with a normal FLC ratio. There is a risk stratification model using the 2 variables of FLC ratio and M-protein level (patients with a normal FLC ratio at baseline and M protein level less than $0.5 \mathrm{~g} / \mathrm{dL}$ ) at 1 to 2 years following diagnosis ; with either risk factor abnormal (intermediate risk); and with both an abnormal FLC ratio and M protein level of $0.5 \mathrm{~g} / \mathrm{dL}$ or higher (high risk). The corresponding progression rates at 5 years were significantly different in the low, intermediate, and high groups: $13 \%, 26 \%$, and $62 \%$, respectively (Dingli et al., 1979-1983).

\subsubsection{Imaging studies in diagnosis of solitary plasmocytoma}

The purposes of imaging in the diagnosis and management of plasmacytoma includes:

- detection of extramedullary or/and intramedullary foci of the disease;

- exclusion of additional lesions and bone marrow involvement;

- evaluation of risk of pathological fractures;

- $\quad$ guiding needle biopsy;

- planning radiotherapy and surgery.

Although definitive radiotherapy usually eradicates the local disease, the majority of patients will develop multiple myeloma because of the growth of previously occult lesions which have not been detected by conventional radiography. So that, diagnosis of solitary plasmacytoma needs accurate exclusion of additional bone or soft-tissue foci and bone marrow involvement.

X-ray examination. Osteolytic lesions are generally diagnosed by radiographic analysis. Plain radiography is everywhere available and allows to visualize large areas of the 
skeleton. In case of solitary plasmacytoma detection, standard radiography examination, as for multiple myeloma staging, should be performed. The skeletal survey should include a posteroanterior view of the chest, antero-posterior and lateral views of the cervical spine, thoracic spine, lumbar spine, humeri and femora, antero-posterior and lateral views of the skull and antero-posterior view of the pelvis. (Grade C recommendation; level IV evidence, Guidelines for the use of imaging in the management of myeloma. British Society for Haematology, 2007).

The weakness of radiographic detection is in relatively low sensitivity: it may reveal lytic disease only when over $30 \%$ of the trabecular bone has been lost (Snapper \& Khan, 1971), so, $10-20 \%$ of lesions are missed. Certain parts of the skeleton are difficult to assess accurately, such as the sternum, ribs and scapulae. In addition, this technique also provides an inadequate assessment of generalised osteopenia (Scane et al, 1994).

Due to the limitations of standard radiographic analysis, magnetic resonance imaging (MRI) and/or computed tomography (CT) have been used for early detection of myelomaassociated bone destruction.

Magnetic resonance imaging. MRI is the preferred imaging modality for the initial assessment and for the follow-up of the osseous and extraosseous extent of SPB.

MRI of the thoracic and lumbosacral spine in the diagnosis of SBP was prospectively evaluated by several studies (Moulopoulos et al, 1993, 1997, 2005). It was shown, that MRI of thoraco-lumbar spine can reveal additional abnormalities more accurate than standard Xrays. After standard local radiotherapy of SBP, patients with additional lesions by pretreatment spinal MRI show earlier progression to systemic disease than those with a negative MR imaging survey at diagnosis.

Typical focus of plasma cell infiltration have a low signal intensity on T1-weighted images and a high signal intensity on T2-weighted and STIR (short time inversion recovery) images (Libshitz et al, 1992) and generally show enhancement on gadolinium-enhanced images. Bone marrow involvement has no specificity of the findings by MRI. The next findings can exist: focal or diffuse changes, variations of the norm; also images of BM can reflect an alternative pathological or physiological process such as iron loading (Isoda et al, 2001), amyloid deposition (Baur et al, 1998) or reactive marrow hyperplasia.

Thus, most investigators agree that a negative MRI of the thoraco-lumbar spine is a prerequisite for the diagnosis of SBP. MRI should be part of the staging procedures in patients with SBP, to better assess both the extent of the local tumor and the revealing of occult lesions elsewhere.

Recommendations for MRI in diagnosis of myeloma and plasmocytoma according to quidelines for the use of imaging in the management of myeloma ( British Society for Haematology, 2007)

- Urgent MR imaging is the diagnostic procedure of choice to assess suspected cord compression in myeloma patients even in the absence of vertebral collapse (Grade B recommendation; level IIB evidence).

- $\quad$ MR imaging of the whole spine should be performed in addition to the skeletal survey as part of staging in all patients with an apparently solitary plasmacytoma of bone irrespective of site of index lesion (Grade B recommendation; level IIB evidence). 
- MR imaging should be used to clarify the significance of ambiguous CT findings, as these two imaging techniques can give complementary information (Grade C recommendation; level IV evidence).

The new diagnostic criteria recommend MRI scanning to include the pelvis. Whole body MR imaging is emerging but currently impractical because of the logistics of long imaging time. (Guidelines on the diagnosis and management of solitary plasmacytoma of bone and solitary extramedullary plasmacytoma, United Kingdom Myeloma Forum,2009)

Computed tomography. Computed tomography provides an advantage in selected situations. Owing to the high levels of radiation exposure, CT cannot be used for screening purposes. Conventional CT has higher sensitivity than plain radiographs for detecting small lytic lesions; it can provide a high predictive value in the clarification of suspicious areas on plain films, and areas, difficult for visualization, such as ribs, sternum and scapulae.

CT should be considered in patients who remain symptomatic despite having no evidence of osteolysis on the skeletal survey.

Urgent CT may be used to establish the presence of suspected cord compression in cases where MR imaging is unavailable.

CT can accuratly depict the extent of associated soft tissue masses and can direct needle biopsy for histological diagnosis (Kyle, 1985) and forms the basis for radiotherapy and surgery.

Recommendations for CT in diagnosis of myeloma and plasmocytoma according to quidelines for the use of imaging in the management of myeloma ( British Society for Haematology, 2007)

- Urgent CT may be used to establish the presence of suspected cord compression in cases where MR imaging is unavailable, impossible due to patient intolerance or contraindicated e.g. intraorbital metallic foreign bodies or cardiac pacemakers (Grade B recommendation; level III evidence).

- CT of the spine may be considered to clarify the presence or absence of bone destruction in cases of clinical concern where MR is negative (Grade $B$ recommendation; level III evidence).

- CT should be used to clarify the significance of ambiguous plain radiographic findings, such as equivocal lytic lesions, especially in parts of the skeleton that are difficult to visualise on plain radiographs, such as ribs, sternum and scapulae(Grade B recommendation; level III evidence).

- CT may identify lesions that are negative on plain radiography, and should be considered in patients who remain symptomatic despite having no evidence of osteolysis on the skeletal survey (Grade B recommendation; level III evidence).

- $\mathrm{CT}$ is indicated to delineate the nature and extent of soft tissue disease, and where appropriate, tissue biopsy may be guided by CT scanning (Grade B recommendation; level IIB evidence).

Positron-emission tomography. PET/CT studies are more sensitive than other imaging modalities for localizing extramedullary sites of the disease. At the present time, it is fair to conclude that clinical experience of PET imaging in patients with plasma cell dyscrasias is in evolution. 
Recommendations for PET in diagnosis of myeloma and plasmocytoma according to quidelines for the use of imaging in the management of myeloma (British Society for Haematology, 2007)

- Based on currently available evidence, PET imaging cannot be recommended for routine use in the management of myeloma patients.

- $\quad$ Either technique may be useful in selected cases that warrant clarification of previous imaging findings, but such an approach should ideally be made within the context of a clinical trial (Grade C recommendation; level IV evidence).

- The evidence for the sensitivity of PET scanning is most convincing in the setting of extramedullary disease. It is therefore reasonable to consider PET scanning in this setting, to clarify the extent of extramedullary disease, in cases where other imaging techniques have failed to clarify the situation (Grade B recommendation; level III evidence).

- If the decision to perform PET scanning has been taken, it is advisable to avoid undertaking the procedure within 4 weeks of chemotherapy or 3 months of radiotherapy (Grade B recommendation; level III evidence).

However, PET/CT has been included as an option in the diagnosis and monitoring of myeloma patients within NCCN guidelines (NCCN, 2011)

Whole-body F-18 FDG PET has the potential to detect the early phase of bone marrow involvement in patients with EMP and unsuspected sites of bone involvement in patients with SBP (Kato et al, 2000; Schirrmeister et al, 2002), upstaging the extent of the disease and significantly affect the therapeutic decisions. According to Schirrmeister et al ., $60 \%$ of patients with known focal osteolytic lesions on plain radiography were upstaged as a result of PET imaging (Schirrmeister et al., 2002).

PET demonstrated a 93\% sensitivity for focal lesions and a $84-92 \%$ sensitivity for diffuse lesions; the specificity ranged from $83-100 \%$ in patients with diffuse FDG uptake (Schirrmeister et al ,2002). False positive PET scans may arise from inflammatory changes due to chemotherapy within the previous 4 weeks or radiotherapy within the previous 2-3 months (Juweid \& Cheson, 2006); also due to active infection (Mahfouz et al, 2005).

\subsection{Treatment of solitary bone plasmacytoma}

Radical radiotherapy remains the treatment of choice for SBP. Knobel et al confirmed excellent local disease control with radiotherapy alone in their review of 206 patients with SBP. (Knobel et al) Local relapse occurred in 21(14\%) out of 148 patients who received radiotherapy alone compared with $4(80 \%)$ out of 5 patients who were treated with surgery $+/$ - chemotherapy. Surgery (radiotherapy versus partial or complete resection and radiotherapy) did not influence the 10 -year probability of local control. Median dose was 40Gy. No dose response relationship was observed for doses higher than 30Gy regardless of tumour size, however this was a retrospective analysis. Previous studies and BCSH recommend radical radiotherapy for SBP encompassing the tumor volume shown on MRI with a margin of at least $2 \mathrm{~cm}$ and treating to a dose of 40Gy in 20 fractions with a higher dose of 50Gy in 25 fractions being considered for $S B P>5 \mathrm{~cm}$. Surgery is not indicated for SBP, but some patients may require decompressive laminectomy, spine fusion or intramedullary 
rod fixation of a long bone (United Kingdom Myeloma Forum. Guidelines on the diagnosis and management of solitary plasmacytoma of bone, extramedullary plasmacytoma and multiple solitary plasmacytomas: 2009 update).

Bisphosphonates are not recommended for the patients with SBP, except in setting of underlying osteopenia (ASCO's Guideline on Bisphosphonates for Multiple Myeloma, 2009).

\subsection{Natural history and prognosis}

The majority of patients with apparent SBP continue to develop myeloma and approximately $5 \%$ of all patients with multiple myeloma have an initial diagnosis of solitary plasmacytoma (Bolek et al. 1996).

The rare cancer network published data on 206 patients with SBP, the largest series to date, in 2006 (Knobel, 2006). Despite treatment, 104 of 206 (50.4\%) patients developed myeloma with a median time to development of 21 months (range, 2-135 months). 5 and 10 year projected probabilities of developing myeloma were $51 \%$ (95\% CI, 43-59\%) and $72 \%$ (95\% CI, $62-82 \%)$. Age $>60$ years was the only independent predictor of development of myeloma in this study. Prognostic value of the persistence of a monoclonal band after treatment could not be assessed due to lack of data. Multivariate analysis of prognostic factors in a series of 60 patients from the MD Anderson Hospital concluded that persistence of a monoclonal band for more than one year after radiotherapy was an adverse prognostic factor (Wilder R.B, 2002). Dengli et al. retrospectively analysed stored serum of 116 patients taken at time of diagnosis of SBP between 1960 and 1995. An abnormal SFLC ratio was found in 54 (47\%) patients and was associated with a higher risk of progression to myeloma $(p=0.039)$ and an adverse overall survival ( $\mathrm{p}=0.033$ ) (Dingli D.,2006). Combining the results of the SFLC ratio at diagnosis with the serum monoclonal protein levels 1-2 years after diagnosis the researchers constructed a risk stratification model (Table 3). Additionally, plasma cells with neoplastic phenotype demonstrable by flow cytometry at bone marrow sites distant to solitary plasmacytoma would also appear to predict for progression to myeloma (Hilli Q.A.,2007). Genetic factors that have prognostic significance in myeloma such as del 13q and $\mathrm{t}(4 ; 14)$ have, as yet, no proven value in solitary lesions.

\begin{tabular}{|l|c|c|}
\hline Variables & Risk group & 5 year progression rate \\
\hline $\begin{array}{l}\text { Normal SFLC ratio } \\
<5 \mathrm{~g} / 1\end{array}$ & Low & $13 \%$ \\
\hline Either variable abnormal & Intermediate & $26 \%$ \\
\hline $\begin{array}{l}\text { Abnormal SFLC ratio } \\
\text { Monoclonal protein }\end{array}>5 \mathrm{~g} / 1$ & High & $62 \%$ \\
\hline
\end{tabular}

Table 3. Risk stratification model for SBP progression to myeloma using SFLC and monoclonal protein level (Dingli D.,2006).

The prognosis after progression to multiple myeloma is also poorer for osseous plasmacytoma than for extra-medullary plasmacytoma as evidenced by multiple retrospective studies. These differences suggest a difference in the biological behavior of the two types of tumor, which is further augmented by immunohistochemical staining and flow 
cytometry analysis. The biological differences found in such studies include higher population of aneuploid cells, proliferating cell-nuclear antigen index, and S-phase fraction (Knowling et al.,1983; Bataille et al.,1981; Frassica et al., 1989).

\section{Solitary extramedullary plasmacytoma}

\subsection{Epidemiology and clinically-laboratory features}

Solitary extramedullary (soft tissue) plasmacytomas (EMP, SEP) are less common than SBP but carry a better prognosis as the majority can be cured by local radiotherapy (Dimopoulos et al., 1999). Although SEP can arise throughout the body almost $90 \%$ arise in the head and neck, especially in the upper respiratory tract including the nasal cavity, sinuses, oropharynx, salivary glands and larynx (Brinch et al, 1990; Wax et al,1993; Susnerwala et al, 1997; Liebross et al, 1999; Galieni et al,2000). The next most frequent site is the gastrointestinal tract. Approximately $10 \%$ of extramedullary plasmacytomas occur in the gastrointestinal tract (Nolan et al., 2005); there are also reports about pancreatic an liver involvment (Manmeet et al.,2010).

A variety of other sites can rarely be involved, including testis, bladder, urethra, breast, ovary, lung, pleura, thyroid, orbit, brain, skin, adrenal glands, retroperitoneum, central nervous system, spleen and the lymph nodes (Cavanna et al, 1990; Rubin et al, 1990; Matsumiyama et al, 1992; Nonamura et al, 1992; Wong et al, 1994; Adkins et al, 1996; Fischer et al, 1996; Tuting \& Bork, 1996; Emery et al, 1999; Muscardin et al, 2000; di Chiara et al, 2001; Ahmed M et al., 2009; Kahara et al., 2001; Pantelidou et al., 2005).

A monoclonal paraprotein is detected in the serum and/or urine in fewer than $25 \%$ of patients (Table 1). Local recurrence rates of $<5 \%$ have been quoted after radiotherapy (Liebross et al, 1999). The risk of distant relapse appears to be $<30 \%$, i.e. significantly less than with SBP (Mayr et al,1990). At least two-thirds of patients survive for $>10$ years (Brinch et al, 1990; Galieni et al,2000).

\subsubsection{Extramedullary plasmacytoma of the head and neck region}

The head and neck region is the most common site for arising of EMP. About $80 \%$ of EMPs occur in the submucosa of the upper aerodigestive tract (Zheng, 2005). The most common site is the sinonasal region. Korolkowa et al. reported that $40 \%$ occur in the nasal cavity and paranasal sinus, $20 \%$ in the nasopharynx and $18 \%$ in the oropharynx (Korolkowa et al., 2004). Other sites are nasopharynx, salivary glands, thyroid glands, tonsils, cervical lynphnodes and larynx. Involvement of neighboring regions such as orbit, palate, skin or scull base can also occur.

The patients mainly manifested as local masses and relevant symptoms; by spreading of the tumor, adjacent bone erosions may occur.

The symptoms are non-specific and depends on site and spread of the tumor. The most common findings are swelling, airway obstructions; in case of sinonasal region it could be nasal obstruction (often, unilateral), nasal discharge, recurrent epistaxis and facial pain.

Also such symptoms as a sore throat and dysphonia to haemoptoea can be found (Straetmans et al., 2008), more rarely cranial nerve palsy and neck lymphadenopathy. 
Clinical manifestations of plasmacytoma of the oral cavity consist of jaw pain, tooth pain, paresthesia, swelling, exophytic soft tissue growth, mobility of teeth, migration of teeth, hemorrhage, burning mouth syndrome and pathologic fracture of the involved bone (Feller et al., 2006). Solitary plasmacytoma affecting the mouth and the jaws are uncommon. The mandible is more frequently involved than the maxilla and the bony lesions of both have a predilection for the posterior areas of the jaws. (Feller et al., 2006).

\subsubsection{Plasmacytoma of the gastrointestinal tract}

Primary plasmacytoma of the gastrointestinal tract is a rare entity (approximately 10\%).

All the segments of the gastro-intestinal tract may be involved with the small intestine being the most common followed by stomach, colon and esophagus. (Krishnamoorthy et al., 2010)

Symptoms are nonspecific, including anorexia, weight loss, epigastric discomfort or gastrointestinal bleeding (Krishnamoorthy et al., 2010); dyspepsia, vomiting and dysphagia for solids in case of esophagus affection (Chetty et al., 2003).

Symptoms of intestinal involvement may include abdominal pain, intestinal obstruction, diarrhea or perforated peritonitis. Jaundice due to extrahepatic biliary obstruction by gastroduodenal plasmacytoma is described. (Unverdi et al., 2010)

On endoscopy, gastrointestinal plasmacytoma commonly present as nodular mass; other findings are ulcerated mass or diffusely thickened mucosal fold (Krishnamoorthy et al., 2010).

Most common findings on barium enema examination include polypoid mass or constricting lesion with or without mucosal or submucosal infiltration. Other less common findings include superficial ulcers, polyps (single or multiple) or intussusception (Gupta et al., 2007).

In several cases, local amyloidosis associated with plasmacytoma of GIT is described. (Carneiro et al., 2009; Nicholl et al., 1991)

\subsubsection{Cutaneous plasmacytoma}

Extramedullary plasmacytomas of the skin are extremely rare and they can be divided into primary cutaneous plasmacytoma (PCP) and metastatic cutaneous plasmacytoma (MCP). While in multiple myeloma cutaneous plasmacytoma represents $5-10 \%$ of cases, PCP is extremely rare variant of plasma cell disorder (Corazza et al.,2002).

Primary cutaneous plasmacytoma is defined as monoclonal proliferation of plasma-cells that arises primarily in the skin without evidence of systemic disease. In contrast, $\mathrm{MCP}$ arises from lymphatic or vascular spread of tumour or, more frequently, by direct extension from underlying bone lesions. However, it can also be seen distinct from a bony focus and even as the initial manifestation of the disease with or without evidence of coexisting MM.

Any area of the skin can be involved, but it has been reported most frequently on the trunk and abdomen followed by face, scalp, neck and extremities. Unusual localizations have been described related to $\mathrm{MCP}$, including scrotum, eyelid, tongue and perianal region. (AlvarezTwose et al., 2008) 
Morphologically, cutaneous plasmacytomas usually consist of erythematous nodules that may ulcerate or plaques dome-shaped and smooth-surfaced ranging from 1 to $5 \mathrm{~cm}$ in diameter. Histopathology reveals the typical pattern represented by a dense monomorphic dermal plasmacytic infiltrate which is usually separated from the overlying epidermis by a border line. Immunohistochemical staining shows the typical monoclonality of the neoplastic cells. Plasmacytoma must also be differentiated from plasma cell infiltrates accompanying other tumors or from reactive granulomas (Corazza et al.,2002).

Cutaneous plasmacytomas should be considered a sign of poor prognosis in plasma cell disorders because they generally occur late in the course of the disease. In case of multiple myeloma, cutaneous metastasis in usually indicates aggressive behavior and short survival (Pereira et al., 2008).

\subsection{Diagnosis and investigation of SEP}

\subsubsection{Diagnostic criteria}

- $\quad$ Single extramedullary mass of clonal plasma cells

- Histologically normal marrow aspirate and trephine

- Normal results on skeletal survey, including radiology of long bones

- No anaemia, hypercalcaemia or renal impairment due to plasma cell dyscrasia

- Absent or low serum or urinary level of monoclonal immunoglobulin

(United Kingdom Myeloma Forum. Guidelines on the diagnosis and management of solitary plasmacytoma of bone, extramedullary plasmacytoma and multiple solitary plasmacytomas: 2009 update)

\subsubsection{Laboratory}

Less than one-quarter of patients have evidence of a low level of monoclonal protein in serum or urine by electrophoresis and/or immunofixation, and (similar to experience

with SBP) are require normal levels of uninvolved immunoglobulins to confirm the absence of occult disease elsewhere (Liebross et al., 1999). The free light chain assays should also prove useful in monitoring such patients, particularly those classified with non-secretory features. In addition, patients should have no sign of underlying myeloma by bone survey and chemistries should reveal no abnormalities attributable to plasma cell dyscrasia (Weber et al., 2005).

Extramedullary plasmacytoma are characterized by a 'myeloma-like' immunophenotype (Boll et al., 2010). It was demonstrated that the infiltrate consists entirely of plasma cells and that there is no B cell component. In this regard CD138, MUM1/IRF4, CD20 and PAX5 are the most useful markers although it should be recognised that CD20 and PAX5 are sometimes expressed in plasma cell malignancies. Monoclonality and /or an aberrant plasma cell phenotype should be demonstrated with useful markers being CD19, CD56, CD27, CD117 and cyclin D1 (Rawstrom A.C.,2008; Stephens E.A., 2005).

EMP may express B-cell markers, such as CD79a and CD20, and MM may express germinal centre B-cell (GCBC)-associated microRNAs, such as miR-93 and miR-181b. The presence of CD19 and lack of miR-223 suggested aberrant B-cell differentiation in CD19(+) /miR-223(-) 
phenotype could be used to distinguish EMP from the CD19(-) /miR-223(+) phenotype of MM (Yu et al., 2011). Immunocytochemistry demonstrated monoclonal expression of light immunoglobulin chains in all cases which, together with demonstration of CD 38 positivity (Tani et al., 1999).

Extramedullary plasmacytoma showed absence of cyclin D1 and infrequent expression of CD56. Furthermore, extramedullary plasmacytomas were characterized by weaker staining for Bcl-2 protein and rare overexpression of p21 and p53. In comparison to extramedullary multiple myeloma, extramedullary plasmacytoma showed a more mature morphology and lower proliferation indices. There was no association between the phenotypic parameters investigated and clinical outcome in extramedullary plasmacytoma (Kremer et al., 2005).

Some non-Hodgkin lymphomas show marked plasmacytic differentiation. In such cases, it may be difficult to differentiate these lymphomas from plasmacytoma or myeloma, especially with limited diagnostic material. However, there may be immunophenotypic differences in the plasma cells in these disorders that distinguish them. The analysis of the immunophenotypes of neoplastic plasma cells in 41 cases of B-lineage non-Hodgkin lymphoma and compares them with those in plasma cell myeloma revealed that plasma cells in lymphoma were significantly more likely to express CD19, CD45, and surface immunoglobulin and less likely to express CD56 than those in myeloma (Seegmiller et al., 2007).

It was shown, that CD19 and CD56 expression can be used reliably to distinguish these entities. Some extramedullary plasmacytomas showed lymphoma-like phenotypes, suggesting that, in reality, they may represent non-Hodgkin lymphomas with extensive plasmacytic differentiation (Seegmiller et al., 2007). EMP must be distinguished from reactive plasmacytoma, plasma cell granuloma and lymphoma (MALT, marginal zone, and immunoblastic).

Boll et al. detailed clinico-pathological assessment of a cohort of 26 patients with EMP. All cases were characterized by a monomorphic plasma cell infiltrate showing strong uniform expression of both CD138 and MUM1/IRF4. There was no obvious B-cell component identified either by morphology or immunohistochemistry. Two cases did express CD20 but they both lacked PAX5 expression. With respect to the antigens aberrantly expressed in myeloma plasma cells; CD56 and CD117 expression was documented in 58\% (15/26) and $29 \%(5 / 17)$ of cases respectively while loss of CD27 was documented in 63\% (12/ 19). Aberrant expression of at least one of these antigens was demonstrable in $92 \%$ of assessable cases $(22 / 24)$. Authors believe that this data along with other recently published studies strongly suggest that EMP should be considered part of the spectrum of plasma cell disorders rather than lymphoma (Boll et al., 2010).

Staining with T-cell markers is unusual but reports of plasmacytomas staining with CD43 and CD45RO do exist (Petruch et al., 1992). Rare cases are described, which were positive for myeloid markers such as CD13, CD33, CD38, and CD138 (Shin et al., 2001). Cytokeratin immunoreactivity in plasmacytomas is generally considered to be rare (Sewell et al., 1986)

Bink et al. studied 38 cases of this type of neoplasm by fluorescence in situ hybridization. Fourteen cases $(37 \%)$ contained IGH breaks, including six with a $t(4 ; 14)$ translocation. No translocations $\mathrm{t}(11 ; 14), \mathrm{t}(14 ; 16), \mathrm{t}(8 ; 14)$, nor breaks involving MALT1, BCL6 or FOXP1 were 
found. Loss of $13 q(40 \%)$, as well as chromosomal gains $(82 \%)$, were common. There was no correlation between chromosomal alterations and clinical features or local relapse. Cytogenetically, extramedullary plasmacytoma and multiple myeloma are closely related. However, the distribution of IGH translocation partners, with the notable absence of $\mathrm{t}(11 ; 14)$, is different (Bink et al., 2008).

Plasma cells have low proliferative activity, making cytogenetic studies inherently difficult to perform. However, numerical and structural chromosomal aberrations have been described in 20 to 60 percent of newly diagnosed multiple myeloma patients (Durie et al., 1992). Complex karyotypes with multiple chromosomal gains and losses are the most frequent changes, but translocations, deletions, and mutations have all been reported. Monosomy or partial deletion of 13 (13q14) is the most common finding, occurring in 15 to 40 percent cases. Deletion of $17 \mathrm{p} 13$, associated with allelic loss of p53, is reported in 25 percent of cases, and may predict a poor outcome (Konigsberg et al., 2000).

The most common structural abnormality is a $\mathrm{t}(11 ; 14)(\mathrm{q} 13 \mathrm{q} 32)$ translocation, resulting in over-expression of cyclin D1, occurring in 10 to 31 percent of cases (Menke et al., 2001;).

Aalto et al. demonstrated chromosome 13 loss in 8/9 EMP cases assessed by comparative genomic hybridization (Aalto et al., 1999). Similarly Bink et al found a high incidence of 13q loss $(40 \%)$ and IGH rearrangements (37\%) amongst 38 cases assessed by FISH based assays (Bink et al., 2008). They also demonstrated a relatively high incidence of the $t(4 ; 14)(p 16 ; q 32)$ but no cases with the $t(11 ; 14)(q 13 ; q 32)$ and high incidence of chromosome gains $(82 \%)$ but no evidence of rearrangements of MALT1, BCL6 or FOXP1 (Bink et al, 2008).

\subsubsection{Imaging studies}

CT or MRI scanning is required to delineate the extent of the lesion but the role of MRI scanning of other areas in the staging of SEP has not been evaluated. There are different meanings. According to guidelines on the diagnosis and management of solitary plasmacytoma of bone and solitary extramedullary plasmacytoma (United Kingdom Myeloma Forum. Guidelines on the diagnosis and management of solitary plasmacytoma of bone, extramedullary plasmacytoma and multiple solitary plasmacytomas: 2009 update), MRI of the spine is not considered to be necessary for the diagnosis of SEP. But other authors find it useful for the accurate staging of EMP, similar to SBP.

\subsection{Treatment of solitary extramedullary plasmacytoma}

Solitary extramedullary plasmacytoma are highly radiosensitive tumours. Local control rates of $80-100 \%$ are consistently reported with moderate doses of radiotherapy (Mayr et al, 1990; Bolek et al, 1996; Jyothirmayi et al, 1997; Liebross et al, 1998).

Solitary extramedullary plasmacytoma should be treated by radical radiotherapy encompassing the primary tumour with a margin of at least $2 \mathrm{~cm}$. The cervical nodes should be included if involved. The first echelon cervical nodes should be included in SEP of Waldeyer's ring. For SEP up to $5 \mathrm{~cm}$ a radiotherapy dose of $40 \mathrm{~Gy}$ in 20 fractions is recommended. For bulky SEP of $>5 \mathrm{~cm}$, a higher dose of up to $50 \mathrm{~Gy}$ in 25 fractions is recommended. 
Radiotherapy alone is the treatment of choice for head and neck SEP. Radical surgery should be avoided in head and neck SEP. For SEP at other sites complete surgical removal should be considered if feasible. Patients with involved surgical margins should receive adjuvant radiotherapy. No recommendation for adjuvant radiotherapy can be made for patients who have undergone complete surgical excision with negative margins.

Adjuvant chemotherapy should be considered in patients with tumours $>5 \mathrm{~cm}$ and those with high grade tumours. Chemotherapy is indicated for patients with refractory and/or relapsed disease. Therapy as for MM is indicated (United Kingdom Myeloma Forum. Guidelines on the diagnosis and management of solitary plasmacytoma of bone, extramedullary plasmacytoma and multiple solitary plasmacytomas: 2009 update).

\subsection{Natural history and prognosis}

In most series, $<10 \%$ of patients have local recurrence of disease and the 10 -year disease free and overall survival ranges from $50-80 \%$, for the $30 \%-50 \%$ of patients who develop disease progression to myeloma. This occurs after a median of 1.5-2.5 years and their clinical course at progression is similar to those of patients diagnosed with de novo symptomatic myeloma (Weber D, 2005). Because of the small number of patients in most series, any statistically significant risk factors for development of myeloma are not clear and are further complicated by the inclusion of patients over many decades during which treatment and diagnostic modalities have become more refined and are likely to impact prognosis. In some series, bulky disease $>5 \mathrm{~cm}$ may have prognostic significance (Tsang, 2001).

\section{Multiple solitary plasmacytomas}

Multiple solitary plasmacytomas, which may be recurrent, occur in up to $5 \%$ of patients with an apparently solitary plasmacytoma and may involve soft tissue or bone.

\subsection{Diagnostic criteria}

- Absent or low serum or urinary level of monoclonal immunoglobulin

- More than one localized area of bone destruction or extramedullar tumor of clonal plasma cells which may be recurrent

- Normal bone marrow

- Normal skeletal survey and MRI of spine and pelvis

- No related organ or tissue impairment

(United Kingdom Myeloma Forum. Guidelines on the diagnosis and management of solitary plasmacytoma of bone, extramedullary plasmacytoma and multiple solitary plasmacytomas: 2009 update).

\subsection{Treatment}

Treatment approaches to patients with multiple solitary plasmacytomas are variable and it is likely the choice of therapy will be influenced by factors such as patient age, sites of 
recurrence, numbers of lesions and disease free interval. Recurrent solitary plasmacytoma out with the original site of radiotherapy, in the continuing absence of systemic disease, may be treated with additional radiotherapy. Patients with more extensive disease or early relapse may benefit from systemic therapy +/- autologous stem cell transplantation, as indicated for myeloma, with small cases series suggesting long term disease control (Dimopouloos, 2003). Newer agents including thalidomide and bortezomib have also been used successfully, prior to transplantation, in small numbers of patients with relapsed plasmacytoma (Chim, 2005; Katodritou, 2007; Pantelidou, 2006).

\section{References}

Christopher DM Fletcher. Diagnostic histopathology of tumors. Volume 2, 2nd edition. Churchill Livingstone

Jaffe E.S., Harris N.L., Stein H., Vardiman J.W. (Eds.). (2001). World Health Organization Classification of Tumours, Pathology and Genetics, Tumours of Haematopoietic and Lymphoid Tissues. Lyon: IARC press

Snapper, I. \& Khan, A. (1971) Myelomatosis: fundamentals and clinical features. University Park Press, Baltimore.

Aalto, Y., Nordling, S., Kivioja, A.H., Karaharju, E., Elomaa, I. \&Knuutila, S. (1999) Among numerous DNA copy number changes, losses of chromosome 13 are highly recurrent in plasmacytoma. Genes, Chromosomes and Cancer, 25, 104-107

Ahmed M, Al-Ghamdi A, Al-Omari M, Aljurf M, Al-Kadhi Y. (2009) Autologous bone marrow transplanation for extramedullary plasmacytoma presenting as adrenal incidentaloma. Ann Saudi Med 29:219-22;

Adkins, J.W., Shields, J.A., Shields, C.L., Eagle, Jr, R.D., Flanagan, J.V. \& Campanella, P.C. (1996) Plasmacytoma of the eye and orbit. International Ophthalmology, 20, 339343.

Alvarez-Twose I.et al. Metastatic cutaneous plasmacytoma presenting as a perianal giant mass (2008) Dermatology Online Journal 14 (9)

Bataille R, Sany J. (1981) Solitary myeloma: clinical and prognostic features of a review of 114 cases. Cancer.; $48: 845-851$

Baur, A., Stabler, A., Lamerz, R., Bartl, R. \& Reiser, M. (1998) Light chain deposition disease in multiple myeloma: MR imaging features correlated with histopathological findings. Skeletal Radiology, 27, 173-176.

Bhaskar A, Gupta R, Sharma A., Kumar L, Jain P. (2009) Analysis of bone marrow plasma cells in patients with solitary bone plasmacytoma. Cancer Therapy Vol 7, 49-52.

Bink K, Haralambieva E, Kremer M, Ott G, Beham-Schmid C, de Leval L, Peh SC, Laeng HR, Jütting U, Hutzler P, Quintanilla-Martinez L, and Fend F.(2008) Primary extramedullary plasmacytoma: similarities with and differences from multiple myeloma revealed by interphase cytogenetics. Haematologica 93(4):623-626

Bolek, T.W., Marcus, R.B. \& Mendenhall, N.P. (1996) Solitary plasmacytoma of bone and soft tissue. International Journal of Radiation Oncology, Biology, Physics, 36, 329-333.

Boll M et al (2010) - Extramedullary plasmacytoma are characterized by a 'myeloma-like' immunophenotype and genotype and occult bone marrow involvement. British Journal of Haematology, 2010, 151: 525-531 
Brinch, L., Hannisdal, E., Foss Abrahamsen, A., Kvaloy, S. \& Langholm, R. (1990) Extramedullary plasmacytomas and solitary plasma cell tumours of bone. European Journal of Haematology, 44, 131-134.

Brinch, L., Hannisdal, E., Foss Abrahamsen, A., Kvaloy, S. \& Langholm, R. (1990) Extramedullary plasmacytomas and solitary plasma cell tumours of bone. European Journal of Haematology, 44, 131-134.

Cavanna, L., Fornari, F., Civardi, G., Di Stasi, M., Sbolli, G., Foroni, R., Voltolini, F. \& Buscarini, L. (1990) Extramedullary plasmacytoma of the testicle. Sonographic appearance and ultrasonically guided biopsy. Blut, 60, 328-330.

Carneiro F.P. (1991) Extramedullary plasmocytoma associated with a massive deposit of amyloid in the duodenum. Postgrad Med J 67, 1075 - 1077

Chang, M.Y., Shih, L.Y., Dunn, P., Leung, W.M. \& Chen, W.J. (1994) Solitary plasmacytomas of bone. Journal of the Formosa Medical Association, 93, 397-402.

Chetty R, Bramdev A, Reddy AD.(2003). Primary extramedullary plasmacytoma of the esophagus. Ann Diagn Pathol. Jun;7(3):174-9.

Chim C.S., Ooi G.C., Loong F., Au A.W.M., Lie A.K.W. (2005) Bortezomib in primary refractory plasmacytoma. Journal of Clinical Oncology;23:2426-2428

Corazza M et al. (2002) Primary cutaneous plasmacytoma on chronic lymphoedema. European Journal of Dermatology. Volume 12, Number 2, 191-3.

D Dingli, R A. Kyle, S. V Rajkumar, G S. Nowakowski, D R. Larson, J P. Bida, M A. Gertz, T M. Therneau, L. J Melton, III, A Dispenzieri, and J A. Katzmann.(2006) Immunoglobulin free light chains and solitary plasmacytoma of bone. Blood. 108(6): 1979-1983

di Chiara, A., Losito, S., Terracciano, L., di Giacomo, R., Iaccarino, G.\& Rubolotta, M.R. (2001) Primary plasmacytoma of the breast. Archives of Pathology and Laboratory Medicine, 125, 1078-1080.

Dimopouloos M.A.,Papadimitriou C., Anagnostopoulos A., Mitsibounas D., Fermand J.P. (2003). High dose therapy with autologous stem cell transplantation for solitary plasmacytoma complicated by local relapse or isolated distant recurrenceю Leukaemia and Lymphoma;44:153-155

Dimopoulos, M.A., Moulopoulos, L.A., Maniatis, A. \& Alexanian, R.(2000) Solitary plasmacytoma of bone and asymptomatic multiple myeloma. Blood, 96, 20372044.

Dingli D., Kyle R.A., Rajkumar V., Nowakowski G.S., Larson D.R., Bida J.P., Gertz M.A., Therneau T.M., Melton L.J., Dispenzieri A., Katzmann J.A. (2006) Immunoglobulin free light chains and solitary plasmacytoma of bone. Blood;108:1979-1983

Dispenzieri A, Kyle R, Merlini G, Miguel JS, Ludwig H, Hajek R, Palumbo A, Jagannath S, Blade J, Lonial S, Dimopoulos M, Comenzo R, Einsele H, Barlogie B, Anderson K, Gertz M, Harousseau JL, Attal M, Tosi P, Sonneveld P, Boccadoro M, Morgan G, Richardson P, Sezer O, Mateos MV, Cavo M, Joshua D, Turesson I, Chen W, Shimizu K, Powles R, Rajkumar SV, Durie BG; International Myeloma Working Group. (2009) International Myeloma Working Group guidelines for serum-free light chain analysis in multiple myeloma and related disorders. Leukemia. 23(2):215-24. 
Durie, BG (1992) Cellular and molecular genetic features of myeloma and related disorders. Hematol Oncol Clin North Am; 6:463-477

E Tani, G C Santos, E Svedmyr, L Skoog.(1999) Fine-needle aspiration cytology and immunocytochemistry of soft-tissue extramedullary plasma-cell neoplasms . Diagnostic Cytopathology,- Vol 20, Issue 3, pp 120-124

Feller L et al. (2006) Extramedullary myeloma in an HIV-seropositive subject. Literature review and report of an unusual case. Int J Radiat Oncol Biol Phys 64:210-7.

Fischer, C., Terpe, H.J., Weidner, W. \& Schulz, A. (1996) Primary plasmacytoma of the testis. Case report and review of the literature. Urologia Internationalis, 56, 263-265.

Frassica DA, Frassica FJ, Schray MF, Sim FH, Kyle RA. (1989) Solitary plasmacytoma of bone: Mayo Clinic experience. Int J Radiat Oncol Biol Phys.;16: 43-48

Frassica DA, Frassica FS, Schray MF, et al. (1989) Solitary plasmacytoma of bone: Mayo Clinic experience. Int J Radiat Oncol Biol Phys.16:43-48

Galieni, P., Cavo, M., Pulsoni, A., Avvisati, G., Bigazzi, C., Neri, S.,Caliceti, U., Benni, M., Ronconi, S. \& Lauria, F. (2000) Clinical outcome of extramedullary plasmacytoma. Haematologica, 85,47-51.

Galieni, P., Cavo, M., Pulsoni, A., Avvisati, G., Bigazzi, C., Neri, S.,Caliceti, U., Benni, M., Ronconi, S. \& Lauria, F. (2000) Clinical outcome of extramedullary plasmacytoma. Haematologica, 85, 47-51. in multiple myeloma and related disorders eukemia 1-10

Gupta V. et al (2007) Primary isolated extramedullary plasmacytoma of colon. World Journal of Surgical Oncology 5:47

Isoda, H., Kojima, H., Shimizu, K., Kurokawa, H., Ikeda, K., Sawada,S., Sakaida, N. \& Okamura, A. (2001) Multiple myeloma: short T2 on MR imaging. Clinical Imaging, 25, 141-143.

Jyothirmayi, R., Gangadharan, V.P., Nair, M.K. \& Rajan, B. (1997) Radiotherapy in the treatment of solitary plasmacytoma. British Journal of Radiology, 70, 511-516.

Kahara T, Nagai Y, Yamashita H, Nohara E, Kobayashi K, Takamura T. (2001) Extramedullary plasmacytoma in the adrenal incidentalom. Clin Endocrinol 55:267270;

Kato, T., Tsukamoto, E., Nishioka, T., Yamazaki, A., Shirato, H.,Kobayashi, S., Asaka, M., Imamura, M. \& Tamaki, N. (2000) Early detection of bone marrow involvement in extramedullary plasmacytoma by whole-body F-18 FDG positron emission tomography. Clinical Nuclear Medicine, 25, 870-873.

Katodritou E., Speletas M., Pouli A., Tsitouridis J., Zervas K., Terpos E. (2007) Successful treatment of extramedullary plasmacytoma of the cavernous sinus using a combination of intermediate dose of thalidomide and dexamethasone. Acta Haematologica; 117:20-23

Krishnamoorthy N, Bal MM, Ramadwar M, Deodhar K, Mohandas KM. (2010) A rare case of primary gastric plasmacytoma: an unforeseen surprise. J Cancer Res Ther. 6(4):549-51.

Kyle, R.A. (1985) Multiple myeloma: current therapy and a glimpse of the future. Scandinavian Journal of Haematology, 35, 38-47. 
Knobel D., Zouhair A. et al. (2006) Prognostic factors in solitary plasmacytoma of bone: a multicenter rare cancer network study. BMC Cancer;6:118

Knowling MA, Harwood AR, Bergsagel DE.(1983) Comparison of extramedullary plasmacytomas with solitary and multiple plasma cell tumors of bone. J Clin Oncol. 1:255-262;

Konigsberg, R, Zojer, N, Ackerman, J, et al.(2000) Predictive role of interphase cytogenetics for survival of patients with multiple myeloma. J Clin Oncol; 18:804-812

Korolkowa O, Osuch-Wójcikiewicz E, Deptała A, Suleiman W. (2004) Extramedullary plasmacytoma of the head and neck, Otolaryngol Pol. 58(5):1009-12. [Article in Polish]

Kremer M, Ott G, Nathrath M, Specht K, Stecker K, Alexiou C, Quintanilla-Martinez L, Fend F J. (2005) Primary extramedullary plasmacytoma and multiple myeloma: phenotypic differences revealed by immunohistochemical analysis. Pathol.2005(1):92-101

Libshitz, H.I., Malthouse, S.R., Cunningham, D., MacVicar, A.D. \& Husband, J.E. (1992) Multiple myeloma: appearance at MR imaging. Radiology, 182, 833-837.

Liebross RH, Ha CS, Cox JD, Weber D, Delasalle K, Alexanian R. (1998) Solitary bone plasmacytoma: outcome and prognostic factors following radiotherapy. Intl J Radiat Oncol Biol Phys.;41: 1063-1067;

Liebross RH, Ita CS, Cox JD, et al. (1999) Clinical Course of extramedullary plasmacytoma. Radiother Oncol.;52:245-249

Liebross, R.H., Ha, C.S., Cox, J.D., Weber, D., Delasalle, K. \& Alexanian, R. (1999) Clinical course of solitary extramedullary plasmacytoma. Radiotherapy Oncology, 52, 245249.

Maayke Boll, Elizabeth Parkins, Sheila J. M. O'Connor,Andy C. Rawstron, Roger G. Owen, (2010) - Extramedullary plasmacytoma are characterized by a 'myeloma-like' immunophenotype and genotype and occult bone marrow involvement. British Journal of Haematology, 151, 525-531.

Manmeet S. Padda,a Tiffani Milless,b Adebowale J. Adeniran,c Sepi Mahooti,c and Harry R. Aslaniana. (2010) Pancreatic and Gastric Plasmacytoma Presenting with Obstructive Jaundice, Diagnosed with Endoscopic Ultrasound-Guided Fine Needle Aspiratio. Case Rep Gastroenterol. Sep-Dec; 4(3): 410-415

Matsumiyama, K., Kanayama, Y., Yamaguchi, S., Ueyama, W., Iwasaki, M. \& Osafune, K. (1992) Extramedullary plasmacytoma (EMP) of urinary bladder. Urology, 40, 6770.

Mayr, N.A., Wen, B.-C., Hussey, D.H., Burns, C.P., Staples, J.J., Doornbos, J.F. \& Vigliotti, A.P. (1990) The role of radiation therapy in the treatment of solitary plasmacytomas. Radiotherapy and Oncology, 17, 293-303.

McLain, R.F. \& Weinstein, J.N. (1989) Solitary plasmacytomas of the spine: a review of 84 cases. Journal of Spinal Disorders, 2, 69-74.

Menke, DM, Horny, HP, Griesser, H, et al. (2001)Primary lymph node plasmacytomas (plasmacytic lymphomas). Am J Clin Pathol; 115:119

Mill WB, Griffith R. (1980) The role of radiation therapy in the management of plasma cell tumors. Cancer. 45:647-652 
Moulopoulos, L.A. \& Dimopoulos, M.A. (1997) Magnetic resonance imaging of the bone marrow in hematologic malignancies. Blood, 90,2127-2147.

Moulopoulos, L.A., Dimopoulos, M.A., Weber, D., Fuller, L., Libshitz,H.I. \& Alexanian, R. (1993) Magnetic resonance imaging in the staging of solitary plasmacytoma of bone. Journal of Clinical Oncology, 11, 1311-1315.

Moulopoulos, L.A., Gika, D., Anagnostopoulos, A., Delasalle, K., Weber, D., Alexanian, R. \& Dimopoulos, M.A. (2005) Prognostic significance of magnetic resonance imaging of bone marrow in previously untreated patients with multiple myeloma. Annals of Oncology, 16, 1824-1828.

Muscardin, L.M., Pulsoni, A. \& Cerroni, L. (2000) Primary cutaneous plasmacytoma: report of case with review of the literature. Journal of the American Academy of Dermatology, 43, 962-965.

Nolan KD, Mone MC, Nelson EW. (2005) Plasma cell neoplasms. Review of disease progression and report of a new variant. Surg Oncol. 14:85-90

Nonamura, A., Mizukami, Y., Shimizu, J., Oda, M., Watanabe, Y., Kamimura, R., Takashima, T. \& Kitagawa, M. (1992) Primary extramedullary plasmacytoma of the lung. Internal Medicine, 31, 1396-1400.

Pantelidou D, C.Tsatalasa, D.Margaritis, A.J.Karayiannakis, V.Kaloutsi, E.Spanoudakis, I.Katsilieris, E.Chatzipaschalis, E.Sivridis, G.Bourikas (2005). Extramedullary plasmacytoma: report of two cases with uncommon presentation. Ann Hematol;84:188-191

Pantelidou D., Tsatalas C., Margaritis D., Anastasiadis A.G., Kaloutsi V., Argyropoulou P., Prassopoulos P., Bourikas G. (2006) Successful treatment of lymph node extramedullary plasmacytoma with bortezomib. Annals of Hematology;85:188-190

Pereira M.A. et al. (2008).Cutaneous metastatic plasmacytomas with tropism for a previously injured limb. Dermatology Online Journal 14 (9)

Petruch UR, Horny HP, Kaiserling E. (1992) Frequent expression of haemopoietic and nonhaemopoietic antigens by neoplastic plasma cells: an immunohistochemical study using formalin-fixed, paraffin-embedded tissue. Histopathology .20:35-40

Rubin, J., Johnson, J.T., Killeen, R. \& Barnes, L. (1990) Extramedullary plasmacytoma of the thyroid associated with a serum monoclonal gammopathy. Archives of Otolaryngology - Head and Neck Surgery,116, 855-859.

Seegmiller A.C, Xu Y, McKenna R.W. and Karandikar N.J.(2007) Immunophenotypic Differentiation Between Neoplastic Plasma Cells in Mature B-Cell Lymphoma vs Plasma Cell Myeloma .J Clin Pathol 127:176-181.

Sewell HF, Thompson WD, King DJ. (1986) IgD myeloma/immunoblastic lymphoma cells expressing cytokeratin. Br J Cancer 53:695-696

Shin J.S, G A. Stopyra, M. J. Warhol, H. A.B. Multhaupt (2001). Plasmacytoma with Aberrant Expression of Myeloid Markers, T-cell Markers, and Cytokeratin. J Histochem Cytochem vol. 49 no. 6: 791-792

Scane, A.C., Masud, T., Johnson, F.J. \& Francis, R.M. (1994) The reliability of diagnosing osteoporosis from spinal radiographs. Age Ageing, 23, 283-286.

Schirrmeister, H., Bommer, M., Buck, A.K., Muller, S., Messer, P.,Bunjes, D., Dohner, H., Bergmann, L. \& Reske, S.N. (2002) Initial results in the assessment of multiple 
myeloma using 18F-FDG PET. European Journal of Nuclear Medicine and Molecular Imaging, 29, 361-366.

Schirrmeister, H., Buck, A.K., Bergmann, L., Reske, S.N. \& Bommer, M. (2003) Positron emission tomography (PET) for staging of solitary plasmacytoma. Cancer Biotherapy $\mathcal{E}$ Radiopharmaceuticals, 18, 841-845.

Straetmans J, Stokroos R.(2008) Extramedullary plasmacytomas in the head and neck region. Eur Arch Otorhinolaryngol.Nov;265(11):1417-23.

Susnerwala, S.S., Shanks, J.H., Banerjee, S.S., Scarffe, J.H., Farrington, W.T. \& Slevin, N.J. (1997) Extramedullary plasmacytoma of the head and neck region: clinicopathological correlation in 25 cases. British Journal of Cancer, 75, 921-927.

The International Myeloma Working Group. Criteria for the classification of monoclonal gammopathies, multiple myeloma and related disorders: a report of the International Myeloma Working Group. (2003) British Journal of Haematology; 121:749-757

Tsang, R.W., Gospodarowicz, M.K., Pintilie, M., Bezjak, A., Wells, W.,Hodgson, D.C. \& Stewart, A.K.I. (2001) Solitary plasmacytoma treated with radiotherapy: impact of tumour size on outcome. International Journal of Radiation Oncology, Biology, Physics, 50, 113-120.

Tuting, A.U. \& Bork, K. (1996) Primary plasmacytoma of the skin. Journal of the American Academy of Dermatology, 34, 386-390.

United Kingdom Myeloma Forum. Guidelines on the diagnosis and management of solitary plasmacytoma of bone and solitary extramedullary plasmacytoma (2004). British Journal of Haematology, 124, 717-726

Unverdi S, Köklü S, Tuncer F, Duranay M. (2010) Gastroduodenal plasmacytoma presenting with jaundice. South Med J. Feb;103(2):159-61.

Vaicys, C., Schulder, M., Wolansky, L.J. \& Fromowitz, F.B. (1999) Falco-tentorial plasmacytoma. Case report. Journal of Neurosurgery, 91, 132-135.

Wax, M.K., Yun, K.N. \& Omar, R.A. (1993) Extramedullary plasmacytomas of the head and neck. Otolaryngology - Head and Neck Surgery, 109, 877-885.

Weber D.M. (2005) Solitary Bone and Extramedullary Plasmacytoma. Hematology. : 373376

Wilder RB, Ha CS, Cox JD, Weber D, Delasalle K, Alexanian R. (2002). Persistence of myeloma protein for more than one year after radiotherapy is an adverse prognostic factor in solitary plasmacytoma of bone. Cancer;94: 1532-1537

Wong, K.F., Chan, J.K., Li, L.P., Yau, T.K. \& Lee, A.W. (1994) Primary cutaneous plasmacytoma - report of two cases and review of the literature. American Journal of Dermatopathology, 16, 391-397.

Yu SC, Chen SU, Lu W, Liu TY, Lin CW. Expression of CD19 and lack of miR-223 distinguish extramedullary plasmacytoma from multiple myeloma. Histopathology. 2011 Mar 14. doi: 10.1111/j.1365-2559.2011.03793.x. [Epub ahead of print]

NHS NICE Improving outcomes in haematological cancers 2003. Available from http://www.nice.org.uk 
United Kingdom Myeloma Forum. Guidelines on the diagnosis and management of solitary plasmacytoma of bone, extramedullary plasmacytoma and multiple solitary plasmacytomas: 2009 update (2009) Available from

http://www.bloodmed.com/contentimage/guidelines/3454.pdf 


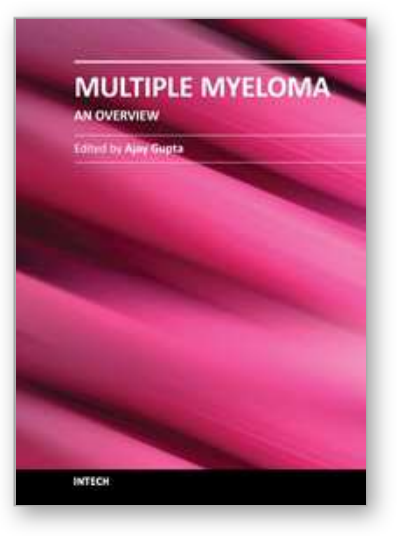

\author{
Multiple Myeloma - An Overview \\ Edited by Dr. Ajay Gupta
}

ISBN 978-953-307-768-0

Hard cover, 274 pages

Publisher InTech

Published online 20, January, 2012

Published in print edition January, 2012

Multiple myeloma is a malignant disorder characterized by the proliferation of plasma cells. Much insight has been gained into the molecular pathways that lead to myeloma and indeed much more remains to be done. The understanding of these pathways is closely linked to their therapeutic implications and is stressed upon in the initial chapters. Recently, the introduction of newer agents such as bortezomib, lenalidomide, thalidomide, liposomal doxorubicin, etc. has led to a flurry of trials aimed at testing various combinations in order to improve survival. Higher response rates observed with these agents have led to their integration into induction therapies. The role of various new therapies vis a vis transplantation has also been examined. Recent advances in the management of plasmacytomas, renal dysfunction, dentistry as well as mobilization of stem cells in the context of myeloma have also found exclusive mention. Since brevity is the soul of wit our attempt has been to present before the reader a comprehensive yet brief text on this important subject.

\title{
How to reference
}

In order to correctly reference this scholarly work, feel free to copy and paste the following:

Galina Salogub, Ekaterina Lokhmatova and Sergey Sozin (2012). Solitary Bone and Extramedullary Plasmacytoma, Multiple Myeloma - An Overview, Dr. Ajay Gupta (Ed.), ISBN: 978-953-307-768-0, InTech, Available from: http://www.intechopen.com/books/multiple-myeloma-an-overview/plasmocytoma

\section{INTECH}

open science | open minds

\author{
InTech Europe \\ University Campus STeP Ri \\ Slavka Krautzeka 83/A \\ 51000 Rijeka, Croatia \\ Phone: +385 (51) 770447 \\ Fax: +385 (51) 686166 \\ www.intechopen.com
}

\author{
InTech China \\ Unit 405, Office Block, Hotel Equatorial Shanghai \\ No.65, Yan An Road (West), Shanghai, 200040, China \\ 中国上海市延安西路65号上海国际贵都大饭店办公楼 405 单元 \\ Phone: +86-21-62489820 \\ Fax: +86-21-62489821
}


(C) 2012 The Author(s). Licensee IntechOpen. This is an open access article distributed under the terms of the Creative Commons Attribution 3.0 License, which permits unrestricted use, distribution, and reproduction in any medium, provided the original work is properly cited. 